\title{
Características estruturais e índice de tombamento de Brachiaria decumbens cv. Basilisk em pastagens diferidas
}

\section{Manoel Eduardo Rozalino Santos ${ }^{1}$, Dilermando Miranda da Fonseca ${ }^{2}$, Valéria Pacheco Batista Euclides ${ }^{3}$, Domicio do Nascimento Júnior², Augusto César de Queiroz², José Ivo Ribeiro Júnior ${ }^{4}$}

\footnotetext{
1 Programa de Pós-graduação em Zootecnia - Universidade Federal de Viçosa. Bolsista da CAPES.

2 Departamento de Zootecnia - Universidade Federal de Viçosa.

${ }^{3}$ Embrapa Gado de Corte.

${ }^{4}$ Departamento de Informática - Universidade Federal de Viçosa.
}

RESUMO - Objetivou-se avaliar o efeito dos períodos de diferimento e de pastejo sobre a densidade populacional de perfilhos, a massa dos componentes morfológicos da forragem e o índice de tombamento em pastagens de Brachiaria decumbens cv. Basilisk. Dois ensaios foram conduzidos: o primeiro denominado ano $1 \mathrm{e}$, o segundo, ano 2. Adotou-se o esquema de parcelas subdivididas, segundo o delineamento em blocos casualizados, com duas repetições para cada combinação dos períodos de diferimento da pastagem com os períodos de pastejo. No ano 1, os períodos de diferimento foram 103, 121, 146 e 163 dias; e no ano 2, foram 73, 103, 131 e 163 dias. Os períodos de pastejo foram 1, 29, 57 e 85 dias. O aumento do período de diferimento elevou a densidade populacional de perfilhos reprodutivos (ano 2: de 37 para 304 perfilhos $/ \mathrm{m}^{2}$ ) e reduziu a de perfilhos vegetativos (ano 1: de 1.253 para 889 perfilhos $/ \mathrm{m}^{2}$; ano 2: de 1.235 para 627 perfilhos $/ \mathrm{m}^{2}$ ). Durante o período de pastejo, ocorreu diminuição no número de perfilhos vegetativo (ano 1: de 988 para 868 perfilhos $/ \mathrm{m}^{2}$ ) e reprodutivo (ano 1: de 216 para 0 perfilhos $/ \mathrm{m}^{2}$; ano 2: de 203 para 0 perfilhos $/ \mathrm{m}^{2}$ ) e aumento no número de perfilhos mortos (ano 1: 463 para 1.088 perfilhos $/ \mathrm{m}^{2}$; ano 2: de 341 para 1.010 perfilhos $/ \mathrm{m}^{2}$ ). Pastagens sob maiores períodos de diferimento e de pastejo apresentaram maior massa de colmo morto (6.093 e $3.819 \mathrm{~kg} / \mathrm{ha}$ de MS nos anos 1 e 2 , respectivamente) e menor massa de lâmina foliar verde (341 e 177 kg/ha de MS nos anos 1 e 2, respectivamente). Pastos de Brachiaria decumbens cv. Basilisk, submetidos a longos períodos de diferimento e de pastejo possuem características estruturais desfavoráveis à produção animal.

Palavras-chave: composição morfológica, estrutura do pasto, número de perfilhos, período de diferimento, período de pastejo

\section{Structural characteristics and falling index of Brachiaria decumbens cv. Basilisk on deferred pastures}

\footnotetext{
ABSTRACT - This worked aimed to evaluate the effects of deferring and grazing periods on the tiller population density, morphological component mass of forage and falling index on Brachiaria decumbens cv. Basilisk pastures. Two assays were carried out: first year and second year. Subdivided plots were used according to a randomized block design with two replicates. The treatments were composed of combinations of deferred periods and grazing periods. In the first year, 103, 121, 146 and 163-day deferring periods were used; and 73,103, 131 and 163-day deferring periods in the second year. The grazing periods were $1,29,57$ and 85 days. The increase in the deferring period increased the population density of reproductive tillers (from 37 to 304 tillers $/ \mathrm{m}^{2}$ in the second year) and reduced the density of vegetative tillers (from 1,253 to 889 tillers $/ \mathrm{m}^{2}$ in the first year; from 1,235 to $627 \mathrm{tillers} / \mathrm{m}^{2}$ in the second year). Throughout the grazing period, decrease in the vegetative (from 988 to 868 tillers $/ \mathrm{m}^{2}$ in the first year) and reproductive tillers (from 216 to 0 tillers $/ \mathrm{m}^{2}$ in the first year; from 203 to 0 tillers $/ \mathrm{m}^{2}$ in the second year) occurred, as well as increase in dead tillers (from 463 to 1,088 tillers $/ \mathrm{m}^{2}$ in the first year and from 341 to 1,010 tillers $/ \mathrm{m}^{2}$ in the second year). Pastures subjected to longer deferring and grazing periods showed higher dead stem mass $(6093$ and $3819 \mathrm{~kg} / \mathrm{ha}$ of dry mass in the first and second years, respectively) and lower green foliar blade mass (341 and $177 \mathrm{~kg} / \mathrm{ha}$ of dry mass in the first and second years, respectively). Brachiaria decumbens cv. Basilisk pastures submitted to long deferring and grazing periods have unfavorable structural characteristics to animal production.
}

Key Words: deferring period, grazing period, morphological composition, number of tillers, pasture structure

Este artigo foi recebido em 14/3/2008 e aprovado em 21/8/2008.

Correspondências devem ser enviadas para:m_rozalino@yahoo.com.br 


\section{Introdução}

O diferimento da pastagem é uma estratégia de manejo que consiste em selecionar determinada área da propriedade e excluí-la do pastejo, geralmente no fim do verão, com o objetivo de garantir acúmulo de forragem para ser utilizada, sob pastejo, durante o período de escassez de recurso forrageiro.

A estrutura do pasto, entendida como a distribuição e o arranjo espacial dos componentes da parte aérea das plantas dentro de uma comunidade (Laca \& Lemaire, 2000), é significativamente alterada durante o período de diferimento da pastagem.

A importância de mensurar as características estruturais do pasto diferido é fundamentada no reconhecimento de que a estrutura do pasto é uma característica central e determinante tanto da dinâmica de crescimento e competição nas comunidades vegetais, quanto do comportamento ingestivo dos animais em pastejo (Carvalho et al., 2001). Por exemplo, as características estruturais do pasto afetam o tamanho do bocado, o número de bocado por unidade de tempo, o tempo de pastejo e, finalmente, o consumo e desempenho animal (Stobbs, 1973).

A estrutura de um pasto diferido pode ser caracterizada pela quantificação das massas de folha, colmo e material morto na forragem. Em condições de pastagens diferidas, outro evento importante é a possibilidade de ocorrência de tombamento dos perfilhos, o que resulta na formação de uma estrutura de pasto bastante peculiar. Esta condição está associada principalmente a pastagens que permaneceram diferidas por longo período.

Além do efeito do período de diferimento da pastagem, é importante reconhecer que, durante o período de pastejo, plantas e animais respondem à estrutura do pasto diferido. A disponibilidade e as características das plantas variam durante uma seqüência de pastejo, em decorrência de sua evolução fenológica e do impacto do próprio pastejo (Carvalho et al., 2006). Essas modificações afetam o comportamento ingestivo dos animais e seu desempenho.

Teoricamente, para cada forrageira e para cada região do país, existe um período mais apropriado para manter o pasto diferido. Este adequado período de diferimento é um dos determinantes da produção e das características estruturais do pasto, que se modificam durante o período de pastejo. Com base nesta hipótese, avaliaram-se as características estruturais de pastos durante o período de pastejo com o objetivo de determinar o período de diferimento mais adequado para o pasto de Brachiaria decumbens cv. Basilisk na região de Viçosa.

\section{Material e Métodos}

$\mathrm{O}$ experimento foi realizado em área de pastagem de Brachiaria decumbens cv. Basilisk (Stapt.) estabelecida em 1997, onde foram conduzidos dois ensaios. O primeiro ocorreu de janeiro a setembro de $2004 \mathrm{e}$ foi denominado ano 1 e o segundo, de janeiro a setembro de 2005, e foi denominado ano 2. A área experimental pertence ao Setor Forragicultura do Departamento de Zootecnia da Universidade Federal de Viçosa (UFV), em Viçosa, Minas Gerais ( $20^{\circ} 45^{\prime}$ S ; $42^{\circ} 51^{\prime}$ W; $651 \mathrm{~m}$ ), e foi dividida em oito piquetes (parcelas) de 0,25 a 0,40 ha e uma área reserva. Os dados climáticos foram registrados durante o período de avaliação (Tabela 1).

Os tratamentos consistiram das combinações dos períodos de diferimento da pastagem com os períodos de pastejo. Utilizou-se o esquema de parcelas subdivididas, segundo o delineamento em blocos casualizados, com duas repetições, de modo que os períodos de diferimento foram casualizados às parcelas. As subparcelas consistiram de medidas ao longo do período de pastejo, dentro de cada período de diferimento, separadamente. No ano 1, os períodos de diferimento foram 103,121,146 e 163 dias e no ano 2 foram 73, 103, 131 e 163 dias. Para a implementação desses tratamentos, os piquetes foram diferidos em épocas distintas e o início do pastejo ocorreu em data única no ano 1 e no ano 2 . Os períodos de pastejo foram $1,29,57$ e 85 dias e corresponderam às ocasiões em que as avaliações foram realizadas na pastagem, ou seja, a partir do primeiro dia de pastejo ( 7 de julho), e repetidas a cada 28 dias, até o término do experimento ( 29 de setembro).

O solo da área experimental, classificado como Latossolo Vermelho-Amarelo, de textura argilosa e com relevo medianamente ondulado, apresentou as seguintes

Tabela 1 - Médias mensais da temperatura média diária, precipitação pluvial e insolação durante os períodos de janeiro a setembro de 2004 (ano 1) e janeiro a setembro de 2005 (ano 2)

\begin{tabular}{|c|c|c|c|c|c|c|}
\hline \multirow[t]{2}{*}{ Mês } & \multicolumn{2}{|c|}{$\begin{array}{c}\text { Temperatura } \\
\left({ }^{\circ} \mathrm{C}\right)\end{array}$} & \multicolumn{2}{|c|}{$\begin{array}{c}\text { Precipitação } \\
(\mathrm{mm})\end{array}$} & \multicolumn{2}{|c|}{$\begin{array}{l}\text { Insolação } \\
\text { (horas/dia) }\end{array}$} \\
\hline & Ano 1 & Ano 2 & Ano 1 & Ano 2 & Ano 1 & Ano 2 \\
\hline Janeiro & 22,1 & 22,7 & 405,9 & 203,1 & - & 4,3 \\
\hline Fevereiro & 22,0 & 22,2 & 357,4 & 200,2 & 3,2 & 6,3 \\
\hline Março & 21,5 & 22,6 & 205,4 & 267,5 & 6,0 & 5,2 \\
\hline Abril & 20,8 & 21,4 & 136,7 & 57,6 & 5,5 & 6,0 \\
\hline Maio & 18,1 & 18,7 & 41,6 & 45,0 & 4,5 & 6,0 \\
\hline Junho & 15,8 & 17,0 & 40,7 & 32,7 & 4,9 & 4,9 \\
\hline Julho & 15,7 & 15,8 & 35,6 & 24,5 & 5,5 & 6,0 \\
\hline Agosto & 16,7 & 17,9 & 0,2 & 37,4 & 7,3 & 6,7 \\
\hline Setembro & 19,8 & 19,6 & 0,0 & 67,5 & 7,5 & 3,2 \\
\hline
\end{tabular}


características químicas na camada 0-20 cm, em amostragem realizada no dia 17 de dezembro de 2003: $\mathrm{pH}$ em $\mathrm{H}_{2} \mathrm{O}: 5,0$; P: 2,44 (Mehlich-1) e K: $98,13 \mathrm{mg} / \mathrm{dm}^{3} ; \mathrm{Ca}^{+2}: 2,45 ; \mathrm{Mg}^{+2}$ :

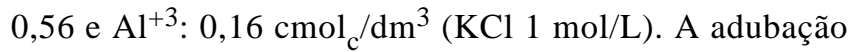
fosfatada foi feita no dia 6 de janeiro de 2004, com a aplicação de $50 \mathrm{~kg} /$ ha de $\mathrm{P}_{2} \mathrm{O}_{5}$, na forma de superfosfato simples. $\mathrm{O}$ adubo potássico, na forma de cloreto de potássio, foi aplicado para elevar a disponibilidade de potássio para $150 \mathrm{mg} / \mathrm{dm}^{3}$, juntamente com o adubo nitrogenado, aplicado nas datas de início de diferimento, em cada piquete, na dose de $70 \mathrm{~kg} / \mathrm{ha}$ de nitrogênio, na forma de uréia e em cobertura. No ano 2, foi realizada apenas a adubação nitrogenada nas datas de início do diferimento, de forma semelhante àquela realizada no ano 1 .

Durante o período de dezembro de 2003 até as datas de início do diferimento do ano 1, e de novembro de 2004 até as datas de início de diferimento do ano 2 , todos os piquetes foram manejados sob lotação contínua, com taxa de lotação variável, a fim de manter as alturas dos pastos em aproximadamente $20 \mathrm{~cm}$. Todos os piquetes permaneceram diferidos até o dia 7 de julho, quando teve início o período de pastejo. Nesse período, todas as pastagens foram manejadas sob lotação contínua com taxa de lotação fixa e semelhante (ano 1: 3,4; 3,7 e 4,0 UA/ha nos meses de julho, agosto e setembro, respectivamente; ano $2: 3,4 ; 3,7$ e 3,8 UA/ha nos meses de julho, agosto e setembro, respectivamente). Foram utilizados bovinos machos nãocastrados, mestiços, com peso médio inicial de $190 \mathrm{~kg}$. Durante o período de pastejo, os pastos diferidos foram suplementados com suplemento múltiplo de baixo consumo. No ano 1, pastagens diferidas por 103, 121, 146 e 163 dias apresentaram oferta média de forragem correspondente a 6,$65 ; 5,98 ; 6,47$ e 7,65 kg de matéria seca de forragem por $\mathrm{kg}$ de peso animal, respectivamente. No ano 2, os valores médios foram de 3,46; 3,75; 4,41 e 5,23 kg de matéria seca de forragem por $\mathrm{kg}$ de peso animal para as pastagens diferidas por 73, 103, 131 e 163 dias, respectivamente.

A densidade populacional de perfilhos foi determinada por meio da colheita de três amostras por piquete em pontos que representavam a condição média do pasto. Foram cortados, no nível do solo, todos os perfilhos contidos no interior de um quadrado de 0,25 m de lado. Esses perfilhos foram acondicionados em sacos plásticos devidamente identificados e, em seguida, levados para o laboratório, onde foram separados e quantificados em perfilhos vegetativos, reprodutivos e mortos. Os perfilhos vivos que tinham a inflorescência visível foram classificados como reprodutivos; os vivos que não tinham a inflorescência visível foram denominados vegetativos; e aqueles cujo colmo estava totalmente necrosado foram classificados como mortos. O somatório dos perfilhos vegetativos e reprodutivos correspondeu ao número de perfilhos vivos.

As medições das alturas do pasto (AP) e da planta estendida (APE) iniciaram após 28 dias do início do período de pastejo e, a partir de então, foram realizadas a cada 28 dias, até o fim do período de utilização das pastagens diferidas no ano 2. Essas avaliações foram feitas em zig-zag pelos piquetes, mensurando-se 50 pontos por unidade experimental. A altura do pasto em cada ponto foi determinada utilizando-se régua com graduação a cada $1 \mathrm{~cm}$ e correspondeu à distância entre a parte da planta localizada mais alto no dossel e o nível do solo. A altura da planta estendida foi mensurada estendendo-se os perfilhos da gramínea no sentido vertical anotando a maior distância do nível do solo até o ápice dos perfilhos. O índice de tombamento das plantas foi calculado pelo quociente entre a altura da planta estendida e a altura da planta.

A massa dos componentes morfológicos da forragem foi estimada em três áreas representativas da condição média do pasto em cada piquete. Em cada área, foi realizado o corte, no nível do solo, de todos os perfilhos contidos no interior de um quadrado de $0,25 \mathrm{~m}^{2}$, que constituíram uma amostra. Cada amostra foi acondicionada em saco plástico identificado e, no laboratório, foi separada manualmente em lâmina foliar verde (LV), colmo verde (CV), lâmina foliar morta (LM) e colmo morto (CM). A inflorescência e a bainha foliar verdes foram incorporadas à fração colmos verdes. A parte da lâmina foliar que não apresentava sinais de senescência foi incorporada à fração lâmina foliar verde. As partes do colmo e da lâmina foliar senescentes e mortos foram incorporadas às frações colmo morto e lâmina foliar morta, respectivamente. Após a separação, os componentes foram pesados, secos em estufa de circulação forçada de ar a $65^{\circ} \mathrm{C}$, por 72 horas, e novamente pesados. A massa de forragem verde (FV) correspondeu ao somatório das massas de lâmina foliar verde e colmo verde. O somatório das massas de lâmina foliar morta e colmo morto foi denominado forragem morta. A massa de forragem total foi calculada pela soma de todos os componentes morfológicos da forragem.

As análises dos dados experimentais foram feitas usando o Sistema para Análises Estatísticas - SAEG, versão 8.1 (UFV, 2003). Para cada característica, foi realizada a análise de variância e, posteriormente, análise de regressão, cujo maior modelo de superfície de resposta às médias dos tratamentos foi o seguinte:

$$
Y_{i}=\beta_{0}+\beta_{1} D_{i}+\beta_{2} P_{i}+\beta_{3} D_{i} P_{i}+e_{i}
$$


em que: $Y_{i}=$ variável-resposta; $D_{i}=$ período de diferimento; $\mathrm{P}_{\mathrm{i}}=$ período de pastejo; $\beta_{0}, \beta_{1}, \beta_{2}, \beta_{3}=$ parâmetros a ser estimados; $\mathrm{e}_{\mathrm{i}}=$ erro experimental;

O grau de ajustamento dos modelos foi avaliado pelo coeficiente de determinação e pela significância dos coeficientes de regressão, testada pelo teste t corrigido com base nos resíduos da análise de variância. Foram calculados os coeficientes de variação referentes à parcela $(\mathrm{CV}$ a) e à subparcela ( $\mathrm{CV}$ b) para cada variável resposta, além dos coeficientes de correlação linear simples entre algumas variáveis, e seus valores foram testados pelo teste t. Todas as análises estatísticas foram realizadas com nível de significância de até $10 \%$ de probabilidade.

\section{Resultados e Discussão}

A densidade populacional das diferentes categorias de perfilhos foi afetada pelo período de diferimento (Tabela 2). O número de perfilhos vegetativos reduziu $(\mathrm{P}<0,05)$ de forma linear com o aumento do período de diferimento. Esse mesmo comportamento foi verificado para o número de perfilhos vivos no ano $1(\mathrm{P}<0,05)$ e no ano $2(\mathrm{P}<0,10)$. Por outro lado, o período de diferimento elevou linearmente o número de perfilhos reprodutivos no ano $2(\mathrm{P}<0,05)$ e o número de perfilhos mortos nos anos $1(\mathrm{P}<0,01)$ e $2(\mathrm{P}<0,05)$. Pastagens diferidas por longos períodos encontravam-se em estádio de maturidade mais avançado. Nessas condições, grande parte dos perfilhos vegetativos desenvolveu-se em perfilhos reprodutivos e estes, por conseguinte, passaram à categoria de perfilhos mortos, seguindo o ciclo fenológico normal de uma gramínea. Esse mesmo padrão de resposta foi confirmado, por exemplo, com o capim-de-rhodes, avaliado sob diferentes idades de crescimento (Tamassia et al., 2001).

Muitos perfilhos vegetativos de menor tamanho foram sombreados e mortos com a competição por luz durante a rebrotação. Segundo Pedreira et al. (2001), maior quantidade de assimilados é alocada para o crescimento de perfilhos já existentes, em detrimento do desenvolvimento de novos perfilhos, em situações de sombreamento. Isso pode ter ocorrido principalmente nos pastos diferidos por maior período. Possivelmente, a ausência de luz na base das touceiras também inibiu o perfilhamento basal, ou seja, reduziu o surgimento de novos perfilhos vegetativos nos pastos submetidos a longos períodos de diferimento. De acordo com Langer (1972), na maioria das espécies, as maiores intensidades luminosas favorecem o perfilhamento. Além disso, a reduzida razão vermelho:infravermelho, característica comum à luz que chega nos estratos inferiores do pasto próximo ao solo, também causa atraso no desenvolvimento das gemas em perfilhos (Deregibus et al., 1983).

Outro fator que pode explicar o aumento da densidade populacional de perfilhos reprodutivos nas pastagens diferidas por maior período é o pico de florescimento do capim-braquiária, que ocorre mais intensamente durante o verão e outono na região de Viçosa, Minas Gerais. Dessa forma, nos pastos diferidos mais cedo no ano (maior período de diferimento), o período de diferimento coincidiu com o período de pico de florescimento. Ao contrário, os pastos diferidos mais tardiamente no ano (menor período de diferimento) estiveram sob pastejo na época de florescimento mais intenso. Com o pastejo,

Tabela 2 - Estimativas da densidade populacional de perfilhos em pastos diferidos de capim-braquiária em cada período de diferimento (D) e de pastejo (P)

\begin{tabular}{|c|c|c|c|c|}
\hline Perfilhos & Equação & $\mathrm{r}^{2}(\%)$ & $\mathrm{CV} \mathrm{a}^{1}(\%)$ & $\mathrm{CV} \mathrm{b}^{2}(\%)$ \\
\hline \multicolumn{5}{|c|}{ Ano 1} \\
\hline Vegetativos & $\hat{\mathrm{Y}}=1851,41-5,7495^{*} \mathrm{D}-1,8380^{+} \mathrm{P}$ & 47,44 & 20,22 & 18,06 \\
\hline Reprodutivos & $\hat{\mathrm{Y}}=154177-2,25695^{* *} \mathrm{P}$ & 38,96 & 70,20 & 73,72 \\
\hline Mortos & $\hat{\mathrm{Y}}=-575,644+8,78358 * * \mathrm{D}+6,70648 * * \mathrm{P}$ & 62,56 & 8,97 & 20,04 \\
\hline Vivos & $\hat{\mathrm{Y}}=1986,33-5,6050 * \mathrm{D}-4,095 * * \mathrm{P}$ & 71,64 & 20,02 & 17,71 \\
\hline \multicolumn{5}{|c|}{ Ano 2} \\
\hline Vegetativos & $\hat{\mathrm{Y}}=1919,05-7,5731 * \mathrm{D}$ & 67,06 & 37,35 & 21,78 \\
\hline Reprodutivos & $\hat{\mathrm{Y}}=32,713+1,24129 * \mathrm{D}-2,37751 * * \mathrm{P}$ & 56,54 & 59,12 & 52,87 \\
\hline Mortos & $\hat{\mathrm{Y}}=-279,68+5,0143 * \mathrm{D}+7,1555 * * \mathrm{P}$ & 80,36 & 34,24 & 27,41 \\
\hline Vivos & $\hat{\mathrm{Y}}=1847,16-6,3318^{+} \mathrm{D}$ & 68,24 & 36,14 & 21,68 \\
\hline
\end{tabular}

${ }^{1}$ Coeficiente de variação do fator período de diferimento; ${ }^{2}$ Coeficiente de variação do fator período de pastejo; ** Significativo pelo teste $\mathrm{t}(\mathrm{P}<0,01)$; * Significativo pelo teste $\mathrm{t}(\mathrm{P}<0,05){ }^{+}$Significativo pelo teste $\mathrm{t}(\mathrm{P}<0,10)$ 
houve eliminação do meristema apical daqueles perfilhos em início da fase reprodutiva, o que diminuiu a ocorrência de perfilhos reprodutivos em pastagens diferidas por períodos mais curtos. Silva (1980), estudando a produção de sementes do capim-gordura, também constatou que a ocorrência de perfilhos reprodutivos, no final do mês de maio foi menor em pastagens cujo último corte ocorreu mais tardiamente no ano.

Durante o período de pastejo, ocorreram mudanças nas densidades populacionais dos perfilhos (Tabela 2). O número de perfilhos reprodutivos reduziu linearmente $(\mathrm{P}<0,01)$ com o aumento do período de pastejo, da mesma forma que o número de perfilhos vegetativos $(\mathrm{P}<0,10)$ e o número de perfilhos vivos no ano $1(\mathrm{P}<0,01)$. O número de perfilhos mortos elevou $(\mathrm{P}<0,01)$, segundo o modelo linear, com o período de pastejo em ambos os anos. Essa elevação no número de perfilhos mortos durante o período de pastejo foi ocasionada pela morte dos perfilhos reprodutivos que já haviam completado seu ciclo fenológico. As condições climáticas desfavoráveis ao crescimento da planta durante o inverno, somadas à remoção da área foliar durante o pastejo, também resultaram em morte de alguns perfilhos vegetativos no decorrer do período de pastejo. A redução no número de perfilhos reprodutivos com o período de pastejo também pode ser explicada pelo eventual consumo da inflorescência desses perfilhos durante o pastejo. Com isso, os perfilhos reprodutivos passaram a ser classificados como perfilhos vegetativos.

Nos estudos de densidade populacional de perfilhos, normalmente os coeficientes de variação das variáveis respostas são altos, em decorrência da instabilidade inerente ao processo de perfilhamento. Neste trabalho, entre as categorias de perfilhos avaliadas, o número de perfilhos reprodutivos apresentou o coeficiente de variação mais elevado (Tabela 2). Além da variabilidade natural, muitas mensurações de número de perfilhos reprodutivos resultaram em valores nulos. De fato, após 57 dias de período de pastejo, não foi observada a ocorrência de perfilhos reprodutivos nos pastos diferidos, o que diminuiu a média geral do experimento, resultando em coeficientes de variação muito altos. Neste caso, a utilização do coeficiente de variação como indicador da precisão experimental não seria apropriada.

Em comparação ao período de diferimento (Tabela 3), o período de pastejo teve efeito mais pronunciado sobre o decréscimo da massa de lâmina foliar verde, uma vez que, no ano 1, a massa de lâmina foliar verde foi influenciada apenas pelo período de pastejo $(\mathrm{P}<0,01)$ e, no ano 2 , o coeficiente angular do período de pastejo $(\mathrm{P}<0,01)$ foi cerca de 3,5 vezes superior ao coeficiente angular do período de diferimento $(\mathrm{P}<0,5)$. Isso ocorreu porque, durante o período de pastejo, dois processos contribuíram para a redução da massa de lâmina foliar verde: senescência e consumo preferencial pelos bovinos. Com o período de diferimento, apenas um processo concorreu para a diminuição da massa de lâmina foliar verde, a senescência, que é maior em pastos mais velhos. De forma similar, Sales et al. (2008) verificaram que a massa de lâmina foliar verde em pasto de Brachiaria decumbens diminuiu de 1.638 para $891 \mathrm{~kg} / \mathrm{ha}$ durante o período de utilização das pastagens nos períodos de transição águas-seca e seca. A não-ocorrência de efeito ( $\mathrm{P}>0,10)$ do período de diferimento sobre a massa de lâmina foliar verde no ano 1 (Tabela 3) pode ser atribuída à elevada produção de forragem verificada neste ano. Os pastos

Tabela 3 - Estimativas das massas dos componentes morfológicos da forragem em pastos de capim-braquiária sob três períodos de diferimento (D) e de pastejo (P)

\begin{tabular}{|c|c|c|c|c|}
\hline Componente morfológico & Regressão & $\mathrm{r}^{2}(\%)$ & $\mathrm{CV} \mathrm{a}^{1}(\%)$ & $\mathrm{CV} \mathrm{b}^{2}(\%)$ \\
\hline \multicolumn{5}{|c|}{ Ano 1} \\
\hline Lâmina foliar verde & $\hat{\mathrm{Y}}=2460,55-27,8084 * * \mathrm{P}$ & 70,77 & 59,70 & 30,80 \\
\hline Colmo verde & $\hat{\mathrm{Y}}=3381,66+15,957 \mathrm{D}+65,14^{+} \mathrm{P}-0,718 * \mathrm{DP}$ & 70,12 & 61,39 & 24,70 \\
\hline Lâmina foliar morta & $\overline{\mathrm{Y}}=1954,8804$ & - & 23,76 & 17,44 \\
\hline Colmo morto & $\hat{\mathrm{Y}}=3771,32+49,423 * * \mathrm{D}+16,3693 * \mathrm{P}$ & 77,64 & 13,40 & 28,88 \\
\hline \multicolumn{5}{|c|}{ Ano 2} \\
\hline Lâmina foliar verde & $\hat{\mathrm{Y}}=2288,05-5,4695 * \mathrm{D}-19,1179 * * \mathrm{P}$ & 79,50 & 27,36 & 41,30 \\
\hline Colmo verde & $\hat{Y}=1424,59+17,85 * D+24,21 P-0,408 * * D P$ & 84,86 & 13,95 & 28,18 \\
\hline Lâmina foliar morta & $\hat{\mathrm{Y}}=985,780+8,75035 * * \mathrm{D}-8,36044 * * \mathrm{P}$ & 58,32 & 14,47 & 18,58 \\
\hline Colmo morto & $\hat{\mathrm{Y}}=1987,13+25,1418 * * \mathrm{D}+17,3933 * * \mathrm{P}$ & 80,64 & 17,86 & 30,53 \\
\hline
\end{tabular}

${ }^{1}$ Coeficiente de variação do fator período de diferimento; ${ }^{2}$ Coeficiente de variação do fator período de pastejo; ** Significativo pelo teste t (P<0,01); * Significativo pelo teste $\mathrm{t}(\mathrm{P}<0,05)$ 
diferidos por maior período apresentaram elevadas quantidades de massa de forragem total, que, mesmo contendo pequeno percentual de lâminas foliares verdes, resultou em aumento na quantidade de massa dessa fração da planta. De outra forma, os pastos diferidos por menor período também apresentaram semelhante massa de lâminas foliares verde, pois eram mais jovens.

No ano $1(\mathrm{P}<0,05)$ e no ano $2(\mathrm{P}<0,01)$, houve interação entre períodos de diferimento e de pastejo para a massa de colmos verdes em pastagens diferidas (Tabela 3). No início do período de pastejo, a massa de colmos verdes foi maior nos pastos diferidos por maior período, comportamento que está de acordo com vários resultados de pesquisa (Oliveira et al., 2005; Tamassia et al., 2001; Cândido et al., 2005). Segundo Da Silva \& Corsi (2003), durante a rebrotação do pasto, quando o dossel passa a interceptar 95\% da luz incidente (índice de área foliar crítico), inicia-se uma competição entre os perfilhos das plantas por luz e, como estratégia, ocorre o alongamento do colmo na tentativa de expor as folhas em um plano mais alto no dossel. O início da utilização de pastagens diferidas ocorre sempre quando o pasto já passou da fase de índice de área foliar crítico e, portanto, a contribuição de colmo e material morto na forragem diferida é maior. Contrariamente, nos pastos diferidos por maior tempo, observou-se diminuição da massa de colmos verdes no último dia de pastejo naqueles pastos diferidos por maior período. Estes possuíam colmos verdes mais velho no início do período de pastejo, constituintes dos perfilhos reprodutivos e vegetativos de maior maturidade, que senesceram durante o período de pastejo. Os pastos sob menor período de diferimento, no entanto, apresentavam perfilhos vegetativos e reprodutivos mais jovens que podem ter permanecido vivos até fim do período de pastejo. Os bovinos também consumiram os colmos verdes presentes na forragem diferida, o que também explica a redução da massa deste componente morfológico durante o período de pastejo.

Pastos diferidos por maior período tiveram longo tempo de crescimento (descanso). Com isso, houve o aumento $(\mathrm{P}<0,01)$ nas massas de lâminas foliares mortas e de colmos mortos (Tabela 3 ) em resposta ao acentuado processo de senescência na fase final de crescimento de pastos mantidos por longo período de rebrotação. Realmente, períodos de crescimento demasiadamente longo comprometem a produção líquida de forragem, em virtude da intensificação, tanto das perdas por senescência quanto das perdas respiratórias de carbono (Parsons et al., 1983). O período de utilização das pastagens diferidas ocorreu no inverno. Nesta estação, é comum a diminuição no processo fotossintético, principalmente em razão da baixa temperatura. Assim, as plantas podem ter passado por um período de acúmulo negativo de carbono durante o período de pastejo, principalmente nas pastagens diferidas por maior período, o que explica, em parte, o aumento da massa de lâmina foliar morta $(\mathrm{P}<0,01)$ no ano 2 , assim como o aumento da massa de colmos mortos no ano $1(\mathrm{P}<0,05)$ e no ano $2(\mathrm{P}<0,01)$ durante o período de pastejo.

Independentemente da magnitude dos períodos de diferimento e de pastejo, em geral, a massa de lâminas foliares verdes foi menor, e a de colmo maior nas pastagens diferidas. Além disso, a massa de lâmina foliar verde, que já era pequena, passou a ser ínfima durante o término do período de pastejo, alcançando 718 e $371 \mathrm{~kg} / \mathrm{ha}$, no $57^{\circ} \mathrm{dia}$ de pastejo, e os valores extremos de 361 e $186 \mathrm{~kg} / \mathrm{ha}$ no último dia de pastejo nas pastagens diferidas no ano $1 \mathrm{e}$ no ano 2 , respectivamente.

As respostas de todos os componentes morfológicos da forragem (Tabela 3) aos períodos de diferimento e de pastejo podem ser explicadas pela análise dos resultados da densidade populacional das categorias de perfilhos em pastos diferidos (Tabela 2). Perfilhos vegetativos não são constituídos de colmos mortos, motivo da correlação negativa (ano 1: $\mathrm{r}=-0,76, \mathrm{P}<0,01 ;$ ano $2: \mathrm{r}=-0,61, \mathrm{P}<0,01$ ) entre essas variáveis. Em geral, perfilhos vegetativos correspondem à categoria de perfilhos mais jovens nas pastagens diferidas e, normalmente, possuem menor número de folhas mortas, o que justifica sua correlação negativa $(\mathrm{P}<0,05)$ com a massa de lâminas foliares mortas no ano $2(\mathrm{r}=-0,49)$. A categoria perfilhos reprodutivos é constituída de perfilhos vivos, porém geralmente mais velhos que os vegetativos. Dessa forma, é coerente que os perfilhos reprodutivos possuam maior número de folhas senescentes, razão da sua correlação positiva $(\mathrm{P}<0,01)$ com a massa de lâminas mortas no ano $2(\mathrm{r}=0,58)$. Além disso, os perfilhos reprodutivos apresentam o típico alongamento do colmo durante seu desenvolvimento fenológico, o que justifica sua correlação positiva com a massa de colmos verdes no ano $1(\mathrm{r}=0,47, \mathrm{P}<0,05)$ e no ano $2(\mathrm{r}=0,76, \mathrm{P}<0,01)$. Os perfilhos mortos não possuem órgãos vivos. Essa característica é a explicação para a correlação negativa $(\mathrm{P}<0,01)$ entre perfilhos mortos e as massas de lâmina foliar verde (ano 1: $r=-0,72 ;$ ano $2: r=-0,76$ ) e colmos verdes (ano 1: $r=-0,74$; ano $2: r=-0,70)$, bem como para a correlação positiva $(\mathrm{P}<0,05)$ destes perfilhos com a massa de colmos mortos (ano 1: $r=0,56$; ano 2: $r=0,88$ ).

No período de pastejo, a altura do pasto (AP) diminuiu $(\mathrm{P}<0,01)$ linearmente em todos os piquetes (Tabela 4$)$. 
Tabela 4 - Estimativas da altura do pasto, da planta estendida e índice de tombamento em pastagens diferidas de capim-braquiária em resposta aos períodos de diferimento (D) e de pastejo $(\mathrm{P})$

\begin{tabular}{|c|c|c|c|c|}
\hline Característica & Equação & $\mathrm{r}^{2}(\%)$ & $\mathrm{CV} \mathrm{a}^{1}(\%)$ & $\mathrm{CV} \mathrm{b}^{2}(\%)$ \\
\hline Altura do pasto & $\hat{\mathrm{Y}}=39,30-0,1602 * * \mathrm{P}$ & 60,40 & 11,14 & 3,84 \\
\hline Altura da planta estendida & $\hat{\mathrm{Y}}=20,74+0,5356 * * \mathrm{D}-0,3257 * * \mathrm{P}$ & 92,52 & 15,83 & 2,84 \\
\hline Índice de tombamento & $\hat{\mathrm{Y}}=-0,3856+0,02303 * * \mathrm{D}$ & 86,39 & 11,26 & 3,99 \\
\hline
\end{tabular}

${ }^{1}$ Coeficiente de variação do fator período de diferimento; ${ }^{2}$ Coeficiente de variação do fator período de pastejo; ** Significativo pelo teste $\mathrm{t}(\mathrm{P}<0,01)$.

Durante esse período, os bovinos consumiram preferencialmente as folhas verdes localizadas, inicialmente, na parte superior do pasto. Com isso, muitos perfilhos também tiveram seu meristema apical eliminado e, conseqüentemente, seu tamanho reduzido. Esse comportamento de consumo foi descrito por Carvalho et al. (2001). Segundo esses autores, inicialmente os animais procuram e consomem o primeiro estrato da vegetação, onde a forragem é de alta qualidade e as massas dos bocados são maiores. Como a rebrotação subsequente à desfolhação foi comprometida pelas condições climáticas desfavoráveis ao crescimento da forrageira no inverno, o efeito do consumo animal na redução da altura do pasto não foi compensado pelo crescimento da gramínea nesse período. Não houve efeito $(\mathrm{P}>0,10)$ do período de diferimento sobre a altura do pasto. A ocorrência do tombamento das plantas impediu que aqueles pastos diferidos por maior período apresentassem maior altura, o que, de fato, era esperado.

A medição da altura da planta estendida (APE) foi realizada para melhor caracterizar o nível de acamamento dos pastos diferidos (Tabela 4). Essa variável respondeu $(\mathrm{P}<0,01)$ linearmente aos períodos de diferimento e de pastejo. Dessa forma, maior período de diferimento resultou em perfilhos maiores, que conferiram às plantas maior comprimento quando estendidas. Contrariamente, maior período de pastejo provocou diminuição da altura da planta estendida porque os perfilhos tiveram seus ápices consumidos durante esse período.

$O$ índice de tombamento dos pastos apenas foi influenciado $(\mathrm{P}<0,01)$ pelo período de diferimento (Tabela 4). Pastagens diferidas por maior período apresentaram plantas de maior peso e altura, que, durante o pastejo, não se mantiveram eretas quando submetidas ao pastejo. $\mathrm{O}$ colmo do capim-braquiária é delgado e flexível, o que explica a facilidade de tombamento dessas plantas quando em idade mais avançada. Essa característica do capimbraquiária responsável pelo tombamento das plantas mais velhas, ou seja, seu colmo pouco espesso, é a mesma que classifica essa gramínea como adequada para o manejo sob diferimento. No modelo ajustado, o período de pastejo não influenciou $(\mathrm{P}>0,10)$ o índice de tombamento dos pastos, provavelmente por essa avaliação ter sido iniciada somente a partir do $29^{\circ}$ dia de pastejo. Neste dia, os pastos diferidos por maior período já se encontravam bastante acamados e, portanto, o índice de tombamento não aumentou mais até o término do período de pastejo. Além disso, tanto a altura da planta estendida quanto a altura do pasto diminuíram durante o período de pastejo e, assim, o índice de tombamento não foi alterado.

Mesmo sem perfilhos tombados, o pasto de capimbraquiária diferido geralmente possui índice de tombamento superior a 1,0 em decorrência de sua forma de crescimento decumbente. Isso faz com que o comprimento do perfilho estendido (APE) seja geralmente maior que a altura da planta. Ressalta-se também que algumas áreas das pastagens diferidas de capim-braquiária se encontravam acamadas antes mesmo do início do período de pastejo. Por outro lado, alguns dos pastos de capimbraquiária diferidos, ainda não submetidos ao pastejo, apresentaram baixo índice de tombamento, mas com alto potencial de acamamento. Esse fato é confirmado nos pastos mais altos.

Entre as estratégias de manejo que poderiam ser utilizadas para reduzir o índice de tombamento em pastos diferidos e para diminuir as possíveis perdas de forragem associadas a esta condição, destacam-se a adoção de menor período de diferimento e a redução da dose de nitrogênio aplicada no início do diferimento do pasto.

A variação nas características estruturais e no índice de tombamento dos pastos diferidos foi influenciada pelas taxa de lotação e pela oferta de forragem utilizadas. Nesse trabalho, pode-se considerar que a taxa de lotação média utilizada foi alta para o período de inverno (ano 1: 3,7 UA/ha; ano 2: 3,6 UA/ha), o que certamente contribuiu para a intensificação das mudanças nas características estruturais dos pastos diferidos. A oferta de forragem no ano 1 foi maior que no ano 2 e maior nas pastagens diferidas por maior período. Isso pode ter resultado em efeito mais pronunciado do período de pastejo sobre as características estruturais dos pastos no ano 1 e naqueles submetidos à 
menor período de diferimento, uma vez que, em situações de menor oferta de forragem, o consumo por unidade de área é geralmente maior.

A altura do pasto correlacionou-se positivamente $(\mathrm{P}<0,01)$ com as massas dos componentes morfológicos e da forragem verde $(\mathrm{LV}, \mathrm{CV}$ e FV) e de forma negativa $(\mathrm{P}<0,05)$ com a massa de colmo morto (CM) (Tabela 5). Nesse experimento, os pastos mais altos foram aqueles avaliados no início do período de pastejo, que possuíam maior massa de componentes morfológicos verdes e menor massa de colmo morto.

A altura do pasto é uma característica estrutural e pode ser usada como uma medida indireta e não destrutiva para a estimativa da massa de forragem na pastagem (Pedreira et al., 2005). Todavia, em pastos diferidos de capim-braquiária, a altura do pasto não se correlacionou $(\mathrm{P}>0,10)$ com a massa de forragem total $(\mathrm{FT})$, em virtude da ocorrência do acamamento dos pastos. Uma característica que pode ser mensurada para a estimativa da massa de forragem em pastagens diferidas é a altura da planta estendida, que foi positivamente correlacionada $(\mathrm{P}<0,01)$ com a massa de forragem total (Tabela 5). Isso ocorreu porque o procedimento para a mensuração dessa característica é indiferente à estrutura do pasto acamado, ao contrário da altura do pasto, que é reduzida quando ocorre o acamamento. Pastos com maior altura da planta estendida possuem perfilhos mais compridos e em estádio de desenvolvimento mais avançado. Assim, é biologicamente coerente a correlação positiva $(\mathrm{P}<0,01)$ da altura da planta estendida com a massa de forragem morta (FM) e de lâmina foliar morta (LM).

$\mathrm{O}$ índice de tombamento do pasto correlacionou-se positivamente com as massas de forragem total $(\mathrm{P}<0,05)$, forragem morta $(\mathrm{P}<0,01)$ e colmo morto $(\mathrm{P}<0,01)$ e negativamente $(\mathrm{P}<0,05)$ com as massas de forragem verde e de lâmina foliar verde (LV). Esse padrão de resposta era esperado, pois pastos com maior índice de tombamento são característicos de pastagens diferidas por maior período, que

Tabela 5 - Estimativas dos coeficientes de correlação linear simples entre a massa de forragem e de seus componentes morfológicos e a altura e o índice de acamamento em pastagens de Brachiaria decumbens diferidas

\begin{tabular}{|c|c|c|c|}
\hline \multirow[t]{2}{*}{ Massa de forragem $(\mathrm{kg} / \mathrm{ha}$ de $\mathrm{MS})$} & \multicolumn{2}{|c|}{ Altura $(\mathrm{cm})$} & \multirow[t]{2}{*}{ Índice de tombamento } \\
\hline & Pasto & Planta estendida & \\
\hline Total & 0,36 & $0,78 * *$ & $0,56^{*}$ \\
\hline Verde & $0,84 * *$ & $-0,20$ & $-0,55^{*}$ \\
\hline Morta & $-0,37$ & $0,75 * *$ & $0,85 * *$ \\
\hline Lâmina foliar verde & $0,84 * *$ & $-0,26$ & $-0,55^{*}$ \\
\hline Lâmina foliar morta & 0,46 & $0,69 * *$ & 0,41 \\
\hline Colmo morto & $-0,63 *$ & 0,48 & $0,73 * *$ \\
\hline
\end{tabular}

** Significativo pelo teste $\mathrm{t}(\mathrm{P}<0,01)$; Significativo pelo teste $\mathrm{t}(\mathrm{P}<0,05)$.

possuem maior produção de forragem total, constituída de maior proporção de componentes morfológicos mortos do que verdes.

O acamamento de um pasto diferido resulta no aumento da densidade volumétrica da forragem, já que uma mesma quantidade de massa de forragem por unidade de área passa a ocupar menor altura do pasto. Essa alteração na densidade volumétrica da forragem, em conjunto com a sua composição morfológica, determina mudanças estruturais no pasto que interferem no comportamento ingestivo animal (Gomide \& Gomide, 2001).

\section{Conclusões}

Pastos de Brachiaria decumbens cv. Basilisk submetidos a longos períodos de diferimento e de pastejo possuem características estruturais desfavoráveis ao consumo animal, como elevado número de perfilhos reprodutivos e mortos, maior massa de colmo, menor massa de lâmina foliar verde e maior índice de tombamento das plantas. Na região de Viçosa, Minas Gerais, o pasto de Brachiaria decumbens cv. Basilisk, adubado com $70 \mathrm{~kg}$ de nitrogênio deve ser diferido por cerca de 70 dias para utilização no início de julho.

\section{Literatura Citada}

CÂNDIDO, M.J.D.; ALEXANDRINO, E.; GOMIDE, J.A. et al. Duração do período de descanso e crescimento do dossel de Panicum maximum cv. Mombaça sob lotação intermitente. Revista Brasileira de Zootecnia, v.34, n.2, p.398-405, 2005. CARVALHO, C.F.; GONSALVES, E.N.; POLI, C.H.E.C. et al. Ecologia do pastejo. In: SIMPÓSIO SOBRE MANEJO ESTRATÉGICO DA PASTAGEM, 3., 2006, Viçosa, MG. Anais... Viçosa, MG: Universidade Federal de Viçosa, 2006. p.43-72. 
CARVALHO, P.C.F.; RIBEIRO FILHO, H.M.N.; POLI, C.H.E.C. et al. Importância da estrutura da pastagem na ingestão e seleção de dietas pelo animal em pastejo. In: REUNIÃO ANUAL DA SOCIEDADE BRASILEIRA DE ZOOTECNIA, 38., 2001, Piracicaba. Anais... Piracicaba: Escola Superior de Agricultura Luiz de Queiroz, 2001. p.883-871.

DA SILVA, S.C.; CORSI, M. Manejo do pastejo. In: SIMPÓSIO SOBRE MANEJO DE PASTAGENS, 20., 2003, Piracicaba. Anais... Piracicaba: Fundação de Estudos Agrários Luiz de Queiroz, 2003. p.155-186.

DEREGIBUS, V.A.; SANCHEZ, R.A.; CASAL, J.J. Effects of light quality on tiller production in Lolium spp. Plant Phisiology, v.27, p.900-912, 1983.

GOMIDE, J.A.; GOMIDE, C.A.M. Utilização e manejo de pastagens. In: REUNIÃO ANUAL DA SOCIEDADE BRASILEIRA DE ZOOTECNIA, 38., 2001, Piracicaba. Anais... Piracicaba: Fundação de Estudos Agrários Luiz de Queiroz, 2001. p.808-825.

LACA, E.A.; LEMAIRE, G. Measuring sward structure. In: T'MANNETJE, L.; JONES, R.M. (Eds.). Field and laboratory methods for grassland and animal production research. Wallingford: CABI Publishing, 2000. p.103-121.

LANGER, R.H.M. How grasses grow. London, 1972. p.60. (Studies in Biology, 34).

OLIVEIRA, M.A.; PEREIRA, O.G.; GARCIA, R. et al. Rendimento e valor nutritivo do capim-Tifton 85 (Cynodon spp.) em diferentes idades de rebrota. Revista Brasileira de Zootecnia, v.29, n.6, p.1949-1960, 2005.

PARSONS, A.J.; LEAFE, E.L.; COLLET, B. et al. The physiology of grass production under grazing. II. Photosynthesis, crop growth and animal intake of continuously-grazed swards. Journal of Applied Ecology, v.20, p.127-139, 1983.

PEDREIRA, C.G.S.; MELLO, A.C.L.; OTANI, L. O processo de produção de forragem em pastagens. In: REUNIÃO ANUAL DA SOCIEDADE BRASILEIRA DE ZOOTECNIA, 38., 2001, Piracicaba. Anais... Piracicaba: Escola Superior de Agricultura Luiz de Queiroz, 2001. p.772-807.

PEDREIRA, C.G.S.; PEDREIRA, B.C.; TONATO, F. Quantificação da massa e da produção de forragem em pastagens. In: SIMPÓSIO SOBRE MANEJO DA PASTAGEM, 22., 2005, Piracicaba. Anais... Piracicaba: Fundação de Estudos Agrários Luiz de Queiroz, 2005. p.195-216.

SALES, M.F.L.; PAULINO, M.F.; PORTO, M.O. et al. Níveis de energia em suplementos múltiplos para terminação de novilhos em pastagem de capim-braquiária no período de transição águas-seca. Revista Brasileira de Zootecnia, v.37, n.4, p.724-733, 2008.

SILVA, S. Efeito da época de corte e de colheita na produção e qualidade de sementes do capim-gordura (Melinis minutiflora Beauv.). 1980. 40f. Dissertação (Mestrado em Zootecnia) - Universidade Federal de Viçosa, Viçosa, MG, 1980.

STOBBS, T.H. The effect of plant structure on the intake of tropical pasture. 1. Variation in the bite size of grazing cattle. Australian Journal Agricultural Research, v.24, p.809-819, 1973.

TAMASSIA, L.F.M.; HADDAD, C.M.; CASTRO, F.G.F. et al. Produção e morfologia do capim de Rhodes em seis maturidades. Scientia Agricola, v.58, n.3, p.599-605, 2001.

UNIVERSIDADE FEDERAL DE VIÇOSA - UFV. SAEG - Sistema de análises estatísticas e genéticas. Versão 8.1. Viçosa, MG: 2003. (Apostila). 142p. 